\title{
Atrial flutter
}

\section{$A$ rare manifestation of digitalis intoxication}

\author{
B. L. Agarwal, B. V. Agrawal, R. K. Agarwal, and S. C. Kansal \\ From the Department of Medicine, M.L.N. Medical College, Allahabad, India
}

Three cases are described of atrial flutter as a result of digitalis intoxication. One of these died during the attempt to restore basic rhythm with intravenous propranolol. The possible mechanism of its production and rarity is discussed.

The classical atrial arrhythmia due to digitalis toxicity is paroxysmal atrial tachycardia with AV block. Atrial flutter has been universally described as rare, though Chung and Thomas (1965) have included atrial fibrillation in the same category. It was reported for the first time by Wedd in 1924 in digitalis toxicity. In a critical review of the cases reported till I959, Coffman and Whipple (1959) accepted I5 only as truly toxic. They added one of their own cases to the list. Since then the number of reported cases has nearly doubled (Aravanis and Michaelides, 1959; Brest, Durge, and Goldberg, 1960; Soffer, 1961; Delman and Stein, 1964; Pomerantz and Varriale, 1967; Paull and Deshpande, 1967; Parameswaran, 1968; Chung, 1969; Lely and Van Enter, 1970).

We ourselves encountered 3 examples which form the basis of this paper in a period of 2 years during which we were actively engaged in a prospective study of digitalis toxicity. It seems that atrial flutter as a result of digitalis intoxication may not after all be so rare.

\section{Case reports}

Case I A 17-year-old girl suffering from rheumatic heart disease with regular sinus rhythm and moderate congestive heart failure had been on maintenance digoxin $0.25 \mathrm{mg}$ orally per day and hydrochlorothiazide $50 \mathrm{mg}$ twice a week for a year. Digoxin was increased to $0.5 \mathrm{mg}$ daily 15 days before admission.

On admission, her pulse was II4 a minute and regular, and the blood pressure was 120/70 $\mathrm{mmHg}$. Jugular venous pressure was raised to $4 \mathrm{~cm}$ above the sternal angle with bilateral pedal oedema and tender hepatomegaly $(5 \mathrm{~cm}$ below the subcostal margin). There was moderate cardiomegaly with murmurs of mitral stenosis

Received 29 June 1971. and incompetence. The lungs showed bilateral basal moist rales.

The first electrocardiogram on admission showed regular sinus rhythm with PR interval of 0.18 second and right ventricular and left atrial hypertrophy. Digoxin was increased to $0.75 \mathrm{mg}$ daily in addition to $50 \mathrm{mg}$ hydrochlorothiazide per day. Anorexia, nausea, and headache suggestive of digitalis intolerance were noted on the eighth day without any cardiac arrhythmia. A day later, on 24 April 1969, pulse became irregular and the patient started vomiting. Electrocardiogram disclosed atrial fibrillation which was considered to be toxic in view of the symptoms, and digitalis was ordered to be stopped. Oral potassium chloride $4 \mathrm{~g}$ daily was added. A tablet of digoxin $(0.25 \mathrm{mg})$ was, however, administered to the patient in error. The repeat electrocardiogram next day revealed atrial flutter with regularly placed atrial complexes at a rate of 315 a minute and varying AV block (Fig. I). On cessation of digitalis, sinus rhythm was restored 24 hours later, while the patient continued oral potassium chloride.

Case 2 A 25-year-old woman who had noted effort intolerance for the past 2 years became severely dyspnoeic with cough and mucopurulent expectoration after an upper respiratory infection. She was admitted with signs of congestive cardiac failure due to tight mitral stenosis and superadded acute bronchitis. She had not been taking digitalis before admission and was in sinus rhythm.

The patient was digitalized orally and after $2.5 \mathrm{mg}$ digoxin in 60 hours developed headache, nausea, and vomiting with irregular pulse. Electrocardiogram revealed atrial fibrillation. The glycoside was stopped for 3 days and her toxic symptoms subsided but atrial fibrillation persisted. Digoxin was restarted as fibrillation was interpreted to be a spontaneous development. After further administration of $1.5 \mathrm{mg}$ of the drug in a period of 2 days, rhythm became regular and the tracing disclosed atrial flutter (230 per minute) with 2: I AV block (Fig. 2). Digitalis and diuretics were stopped and oral potassium chloride $4 \mathrm{~g}$ 


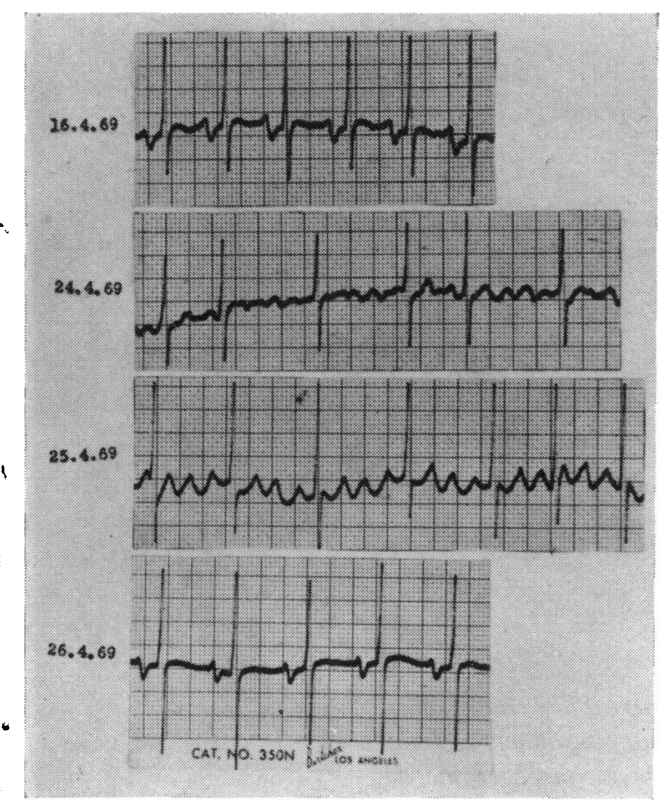

FIG. I Atrial flutter (third strip) induced after administration, in error, of digoxin $0.25 \mathrm{mg}$ to toxic atrial fibrillation. First and last strips are of pre- and post-toxic sinus rhythms (Case I). All are VI leads.

FIG. 2 Toxic atrial flutter (atrial rate 230 a minute with $2: 1$ AV block, 4th strip) was preceded by toxic fibrillation. Therewas reversion to sinus rhythm after passing through atrial fibrillation (fifth strip) and supraventricular tachycardia I: I (sixth strip). All are VI leads except that of tachycardia which is lead II (Case 2).

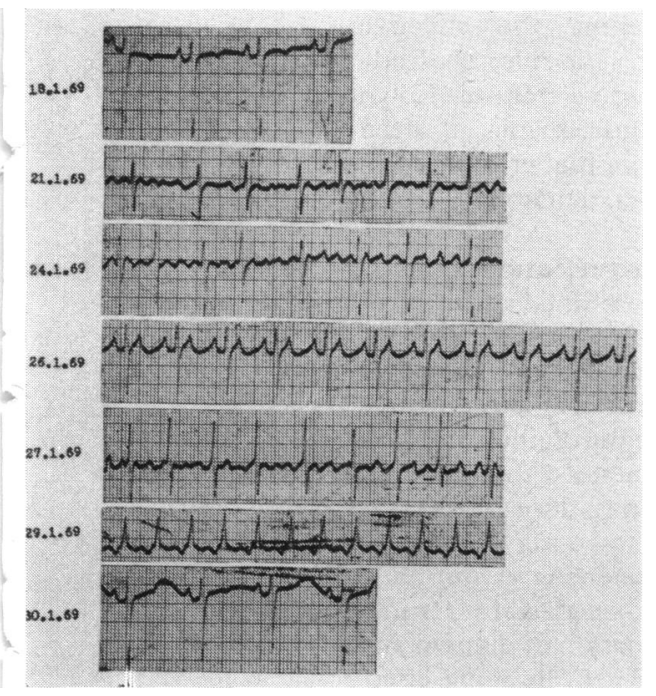

daily was started. Repeat electrocardiograms on subsequent days revealed atrial fibrillation (27 January 1969), supraventricular tachycardia with I : I response (29 January 1969), and finally sinus rhythm on 30 January 1969.

Case 3 A 45-year-old man was a known case of rheumatic mitral stenosis who was in right ventricular failure and atrial fibrillation for at least 5 years. He had been receiving digoxin and chlorthalidone or chlorothiazide for the same period.

In spite of maintenance therapy with $0.25 \mathrm{mg}$ digoxin daily and $50 \mathrm{mg}$ chlorothiazide, signs of right ventricular failure were conspicuous at the time of admission to the hospital. He also complained of loss of appetite. The possibility of digitalis toxicity was considered but he was continued on the same doses of the two drugs as the electrocardiogram did not reveal any toxic features except for the basic rhythm of fibrillation. Five days later lassitude and nausea developed. Electrocardiogram showed atrial flutter (315 a minute) with a changing AV block (Fig. 3). After administration of $\mathbf{I} \cdot \mathbf{2} \mathrm{mg}$ atropine intravenously, propranolol in two doses of I $\mathrm{mg}$ each was slowly injected for this toxic arrhythmia. But the patient developed complete heart block with idioventricular rhythm and expired in a few minutes as a result of rapidly developing and irreversible toxicity to this drug.

Comment All the three examples of atrial flutter are considered to be digitalis induced as the patients exhibited symptoms of toxicity. Maintenance doses of digitalis were rather more in the first case and an increment of glycoside was administered in error after development of toxic fibrillation. Similarly in the second case toxic fibrillation was considered as spontaneous rhythm and digitalis continued. Ventricular rates unlike that of ordinary flutter were on the low side, 85 in the first case and 115 in the next two cases. Fatal outcome of the third case on treatment with propranolol may be an additional point in favour of toxicity.

\section{Discussion}

Digitalis is usually administered to patients for treatment of atrial flutter. It may frequently be the result of digitalis toxicity and the failure to recognize it as such may give rise to serious consequences. Criteria for the diagnosis of an arrhythmia stemming from digitalis intoxication are well laid down (Lown and Levine, 1958; von Capeller, Copeland, and Stern, 1959; Coffman and Whipple, 1959; Agarwal and Agrawal, 1972). In most instances distinction of toxic flutter from the more common PAT with AV block is easy and is based primarily on electrocardiographic features of atrial rate faster than 200 a minute and the presence of saw-tooth undulations of the baseline in at least one lead. Doubt 
may still be cast that it may be an unrecognized PAT with AV block (Friedberg and Donoso, 1960). If atrial rate is the main criteria in distinguishing the two, authenticity of a large number of cases of toxic PAT with block where the reported atrial rates have been as high as 400 (Simonson and Berman, 195I) may also be questioned. El-Sherif (1970) has referred to the significant overlap between supraventricular tachycardia with block and atrial flutter at the high rate levels. Fortunately, from the therapeutic point of view, differentiation between these two arrhythmias - if toxic - is of academic interest only. In case of doubt it is always safer to withhold digitalis and start an intravenous infusion of potassium chloride, as continued use of digitalis may be disastrous.

Even after application of stringent criteria for the diagnosis, it may still be argued that the arrhythmia may be associated with digitalis administration, and not necessarily caused by intoxication. A number of factors considered together will help to establish the true nature. They are the clinical set up, concurrent symptoms of digitalis overdosage, ventricular premature beats, and, in the final analysis, rapid response to potassium infusion. Demonstration of ventricular ectopic beats in the same tracing would have been very useful objective evidence of toxicity. However, in a series of 40 patients with spontaneous flutter, 22 per cent had premature beats (Lown and Levine, 1958) and nearly the same percentage of records of toxic flutter displayed the ectopics (Coffman and Whipple, 1959).

It is essential to take continuous long strips of at least 5 to 6 seconds' duration for the diagnosis of flutter. Short segments of impure flutter (flutter fibrillation) may have $\mathbf{P}$ waves of such uniform contour and regularity that they may closely simulate flutter.

Mechanism According to the generally accepted view both atrial flutter and paroxysmal atrial tachycardia are the result of a rapid discharge from an ectopic focus. It is situated mostly in the cephalic portion of the atrium near the sinus node in patients with paroxysmal atrial tachycardia, while in flutter it is caudally located. There is no satisfactory explanation for the relative rarity of the latter. An inviting hypothesis may be that caudal portions of the atrial muscle - excluding the region of AV node and coronary sinus - are less prone to develop automaticity and even when it develops it is at a subdued rate.

One is on firmer ground in explaining it on the basis of action of digitalis on atria, which

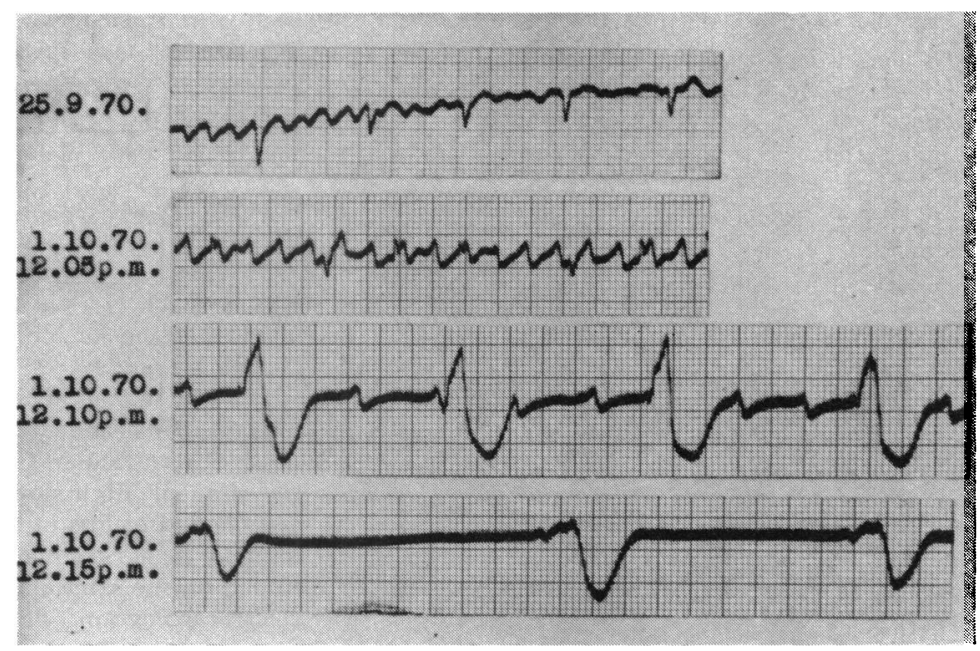

FIG. 3 Basic rhythm-atrial fibrillation (lead $V_{I}$ ). Toxic flutter with varying block (second strip). 2 mg intravenous propranolol induced a slow atrial rhythm, complete $A V$ block with idioventricular rhythm. The last strip was recorded immediately before death (Case 3).

depends on which is predominant: the direct myocardial action or the indirect effect mediated reflexly through vagus. Potassium depletion, both as a result of toxic doses of digitalis and the use of potassium depleting diuretics, results in a loss of atrial responsiveness to the vagal influence. With the diminution or abolition of this vagal effect, direct muscular action of increase in automaticity by digitalis is often exhibited. This is the basis of the frequent development of toxic PAT with AV block. Furthermore, digitalis by slowing conduction and lengthening the effective refractory period would, as a rule, preclude high atrial rates beyond 200 a minute (Lown and Levine, 1958). The infrequency of atrial flutter where atrial rates are higher than 250 a minute is, therefore, understandable.

Propranolol, atrial flutter, and digitalis toxicity Propranolol, combined with appropriate supplements of potassium, has been described by the manufacturers (Imperial Chemical Industries Ltd) in their latest manual as the treatment of choice for digitalis induced arrhythmias. It is recommended that the drug be given intravenously in a dose of 3-5 $\mathrm{mg}$ but may be increased up to Io mg. Watt et al. (1970) succeeded in converting 6 out of 7 consecutive cases of nontoxic atrial flutter into sinus rhythm by a combination of digoxin and propranolol and consider it to be more effec- 
tive than existing forms of drug therapy. The senior author Watt (1968) had also reported earlier the hazards of treating 2 cases of arrhythmia caused by digitalis intoxication with small doses of oral propranolol. One of their patients expired in a few hours and the other was rescued just in time by administration of atropine sulphate. Our third case died in spite of pretreatment with atropine. The solitary example of this series gives support to the recommendations of Watt (1968) that treatment of toxic arrhythmias should be initiated with a small test dose of $5 \mathrm{mg}$ or even less of oral propranolol.

\section{References}

Agarwal, B. L., and Agrawal, B. V. (1972). Digitalis induced paroxysmal atrial tachycardia with A-V block. British Heart fournal.

Aravanis, C., and Michaelides, G. (I959). Paroxysmal auricular flutter and right bundle-branch block following digitalis therapy. American fournal of Cardiology, 4, 124.

Brest, A. N., Durge, N. G., and Goldberg, H. (1960). Conversion of atrial fibrillation to atrial flutter as a manifestation of digitalis toxicity. American Fournal of Cardiology, 6, 682.

Chung, E. K. (1969). Digitalis Intoxication. Excerpta Medica, Amsterdam.

Chung, E. K., and Thomas, J. (1965). Arrhythmias caused by digitalis toxicity. Geriatrics, 20, 1006.

Coffman, J. D., and Whipple, G. H. (1959). Atrial flutter as a manifestation of digitalis toxicity. Circulation, 19, 188.

Delman, A. J., and Stein, E. (1964). Atrial flutter secondary to digitalis toxicity: report of 3 cases and review of the literature. Circulation, 29, 593.

El-Sherif, N. (1970). Supraventricular tachycardia with AV block. British Heart fournal, 32, 46.
Friedberg, C. K., and Donoso, E. (1960). Arrhythmias and conduction disturbances due to digitalis. Progress in Cardiovascular Diseases, 2, 408.

Lely, A. H., and Van Enter, C. H. J. (1970). Large scale digitoxin intoxication. British Medical fournal, 3, 737.

Lown, B., and Levine, H. D. (1958). Atrial Arrhythmias, Digitalis and Potassium. Landsberger Medical Books, New York.

Parameswaran, R. (1968). Atrial flutter due to digitalis toxicity. Cardiologia, 53, 57.

Paull, A. M., and Deshpande, S. Y. (1967). Atrial flutter with complete AV heart block due to digitalis toxicity. Report of a case. Unique case is controlled by withholding digitalis. Rhode Island Medical fournal, 50, 258.

Pomerantz, B., and Varriale, P. (1967). Atrial flutter as manifestation of digitalis toxicity. New York State Fournal of Medicine, 67, 713.

Simonson, E., and Berman, R. (195I). Differentiation between paroxysmal auricular tachycardia with partial AV block and auricular flutter. American Heart fournal, 42, 387.

Soffer, A. (196I). The changing clinical picture of digitalis intoxication. Archives of Internal Medicine, ro7, 68r.

Somlyo, A. P. (1960). The toxicology of digitalis. American fournal of Cardiology, 5, 523.

von Capeller, D., Copeland, G. D., and Stern, T. N. (1959). Digitalis intoxication: a clinical report of 148 cases. Annals of Internal Medicine, 50, 869.

Watt, D. A. L. (1968). Sensitivity to propranolol after digoxin intoxication. British Medical fournal, 3, 413 .

Watt, D. A. L., Livingstone, W. R., MacKay, R. K. S., and Obineche, E. N. (1970). Use of propranolol in atrial flutter. British Heart fournal, 32, 453.

Wedd, A. M. (1924). Clinical auricular flutter. Annals of Clinical Medicine, 3, 69.

Requests for reprints to Professor B. L. Agarwal, 4 Professor's Bungalow, Medical College Enclave, Allahabad, India. 